\title{
KEMAMPUAN AUDIT TENURE MEMODERASI HUBUNGAN PENGALAMAN DAN SKEPTISISME AUDITOR DENGAN KUALITAS AUDIT
}

\author{
I Gusti Ayu Nyoman Budiasiha,, ${ }^{a}$, Ketut Budiarthab \\ a,bUniversitas Udayana, Jn. P. B. Sudirman, Denpasar-Bali, Indonesia \\ *(iganbudiasih17@gmail.com)
}

\begin{abstract}
ABSTRAK
Pentingnya laporan keuangan bagi banyak pihak, menyebabkan laporan tersebut harus disajikan secara relevan dan reliabel. Kualitas audit yang baik dapat menyebabkan laporan keuangan semakin dipercaya keasliannya. Kualitas audit tergantung pada independensi dan kompetensi auditor. Independensi dan kompetensi seorang auditor tergantung pada pengalaman maupun sikap skeptis yang dimiliki auditor tersebut. Pengalaman auditor akan meningkat dikarenakan telah terbiasa dengan pekerjaannya sehingga auditor akan bekerja secara efisien dan lebih tahan terhadap tekanan klien. Sampel yang dipilih menggunakan teknik sampel jenuh dengan jumlah sampel sebanyak 85 auditor. Pengumpulan data dilakukan dengan menyebarkan kuesioner kepada auditor yang menjadi sampel penelitian. Teknik analisis datanya menggunakan analisis regresi tanpa dan dengan variabel moderasi. Berdasarkan hasil analisis data dan pembahasan yang telah dilakukan, maka dapat disimpulkan bahwa kualitas audit di KAP Provinsi Bali memiliki hubungan secara positif dengan pengalaman dan skeptisisme auditor, audit tenure tidak mampu memoderasi hubungan pengalaman auditor dengan kualitas audit auditor di KAP Provinsi Bali, dan audit tenure mampu memoderasi hubungan skeptisisme auditor dengan kualitas audit auditor di KAP Provinsi Bali.

Kata Kunci: audit tenure, pengalaman, skeptisisme auditor, kualitas audit
\end{abstract}

\begin{abstract}
The importance of financial statements for many, causing the report to be presented in a relevant and reliable manner. A good audit quality can lead to more authentic financial reports. The quality of the audit depends on the independence and competence of the auditor. The independence and competence of an auditor depends on the experience and skepticism of the auditor. The experience of the auditor will increase due to the familiarity with the work so that the auditor will work efficiently and more resistant to client pressure. The samples were selected using a sample saturated technique with a total sample of 85 auditors. Data collection was done by distributing questionnaires to the auditor who became the research sample. Data analysis techniques use regression analysis without and with moderation variables. Based on the results of data analysis and discussion that have been done, it can be concluded that the audit quality in KAP Bali Province has a positive relationship with the experience and skepticism of
\end{abstract}


auditors, audit tenure unable to moderate the relationship of auditor experience with audit auditor quality in KAP Bali Province and audit tenure able to moderate the relationship of auditor skepticism with audit auditor quality in KAP Bali Province.

Keywords: audit tenure, experience, auditor skepticism, audit quality

\section{PENDAHULUAN}

Financial Accounting Standard

Board (FASB) menetapkan dua karakteristik penting yang harus dimiliki laporan keuangan agar memberikan manfaat dan informasi yang berguna bagi para pemakai informasi keuangan. Reliable (dapat dihandalkan) dan relevance (relevan) merupakan dua karakteristik yang harus dimiliki oleh laporan keuangan suatu entitas (Singgih dan Bawono, 2010). Apabila manajemen salah menyajikan laporan keuangan, maka akan mengakibatkan kerugian bagi pihak yang berkepentingan terhadap informasi tersebut. Menghadapi situasi tersebut, auditor merupakan pihak ketiga yang dapat mengurangi dampak kesalahan yang ada pada laporan keuangan. Auditor memiliki tugas melakukan pemeriksaan dan memberikan pendapat atas laporan keuangan yang dihasilkan oleh entitas dengan standar auditing yang berlaku.

Fenomena mengenai kualitas audit seperti pada Justinus Aditya
Sidharta yang merupakan salah satu akuntan publik yang terindikasi telah melakukan suatu kesalahan saat melakukan audit pada laporan keuangan PT Great River Internasional,Tbk. Bapepam menemukan bahwa dilakukannya penggelembungan pada akun penjualan, piutang dan aset pada laporan keuangan Great River hingga ratusan milyar rupiah (Piorina dan Ramantha, 2015). Penggelembungan tersebut menyebabkan perusahaan tersebut pada akhirnya mengalami kesulitan arus kas dan gagal dalam membayar utang. Bapepam kemudian menyatakan bahwa akuntan publik yang telah melakukan pemeriksaan terhadap laporan keuangan Great River ikut menjadi tersangka. Adanya kasus tersebut menyebabkan Menteri Keuangan RI membekukan izin akuntan publik Justinus Aditya Sidharta sejak tanggal 28 November 2006 selama dua tahun karena terbukti melanggar Standar Profesi Akuntan Publik (SPAP) yang berkaitan dengan laporan Audit atas Laporan 
Keuangan Konsolidasi PT. Great River tahun 2003. Timbulnya fenomena yang seperti itu, menimbulkan pertanyaan apakah trik-trik rekayasa dalam kasus tersebut tidak mampu dideteksi oleh akuntan publik atau telah terdeteksi namun ikut diamankan oleh akuntan publik. Apabila yang terjadi yakni akuntan publik ikut mengamankan praktik rekayasa tersebut, maka yang menjadi permasalahan adalah independensi yang dimiliki auditor tersebut (Elfarini, 2007). DeAngelo (1981) menyatakan bahwa kualitas audit dapat ditunjukkan oleh independensi dan kompetensi auditor. Apabila auditor berlaku tidak independen sama saja dengan menyalahgunakan keahlian teknis yang dimiliki. Independensi dan kompetensi seorang auditor tergantung pada pengalaman maupun sikap skeptis yang dimiliki auditor tersebut.

Kasus lainnya dalam dunia bisnis terkait kegagalan auditor dalam mendeteksi kecurangan terbukti dengan adanya beberapa skandal keuangan yang melibatkan akuntan publik seperti yang terjadi pada Olympus Corp. Perusahaan produsen kamera dan peralatan kesehatan asal Jepang telah menyembunyikan kerugian dengan menganggapnya sebagai aset sejak tahun 1990-an dan akhirnya terungkap pada akhir tahun 2011. Olympus Corp membayar 687 juta dollar AS atau sekitar 6 triliun rupiah sebagai biaya penasihat keuangan untuk menyembunyikan kerugian (Piorina dan Ramantha, 2015). Olympus Corp. secara bergantian diaudit oleh KAP yang tergolong big five, yaitu Arthur Andersen, KPMG dan Ernest \& Young. Namun temuantemuan menunjukkan terjadi kegagalan dalam mendeteksi maupun mengungkapkan kecurangan laporan keuangan (Piorina dan Ramantha, 2015). Kegagalan tersebut bisa terjadi karena kurangnya independensi, keahlian, pengetahuan ataupun pengalaman auditor dalam mengaudit laporan keuangan (Queena dkk., 2012).

Pengalaman auditor dalam melakukan audit laporan keuangan baik ditunjukkan dari segi lamanya waktu penyelesaian audit maupun banyaknya penugasan yang pernah ditangani, memperlihatkan bahwa seseorang lebih banyak pengalaman dalam suatu bidang subtantif (Badjuri, 2011). Auditor yang memiliki lebih banyak pengalaman dianggap dapat menghasilkan berbagai macam harapan dalam menjelaskan temuan auditnya. Auditor dengan pengalaman dua tahun memiliki sikap profesional, komitmen terhadap kinerja 
organisasi, dan kualitas audit (Badjuri, 2011). Ramdanialsyah (2010), dan Agustin (2013) telah meneliti tentang pengaruh pengalaman auditor dengan kualitas audit dengan menunjukkan hasil bahwa pengalaman auditor berpengaruh dengan kualitas audit.

Tidak cukup dengan memiliki pengalaman yang cukup agar auditor dapat menghasilkan kualitas audit yang baik, Yusuf (2010:53) menyatakan bahwa sikap skeptis merupakan sikap yang dapat menyebabkan seorang auditor menggunakan keahlian profesionalnya dengan cermat dan seksama. Bunga dan Januarti (2013) juga menemukan bahwa sikap skeptis yang dimiliki oleh auditor memiliki pengaruh dengan kualitas audit yang dihasilkan. Sikap skeptis seorang auditor tidak hanya digunakan dalam pelaksanaan audit dan penyusunan laporan, namun dalam melakukan berbagai pekerjaan lapangan serta untuk menemukan bukti audit yang kompeten dan cukup. Pada saat melakukan audit, tingkat kesalahan akan semakin kecil apabila sikap skeptis yang dimiliki auditor semakin tinggi (Bell dkk., 2005). Kualitas audit akan menurun saat auditor kurang memiliki sikap skeptis (Carpenter dkk., 2002). Marghfirah dan Syahril (2008) menemukan bahwa di antara skeptisisme dan pemberian opini auditor yang tepat terdapat hubungan yang signifikan. Ketepatan pemberian opini tersebut selanjutnya akan meningkatkan kualitas audit.

Securities and Exchange Commissions (SEC) menemukan bahwa urutan ketiga dari penyebab kegagalan audit adalah tingkat skeptisisme profesional yang kurang memadai. Dari 45 kasus audit yang diteliti SEC, 24 kasus (60\%) diantaranya terjadi karena auditor tidak menerapkan tingkat skeptisisme profesional yang memadai (Bunga dan Januarti, 2013). Rendahnya sikap skeptisme profesional yang dimiliki akan mengurangi kemampuan auditor dalam mendeteksi kecurangan sehingga auditor tidak mampu memenuhi tuntutan untuk menghasilkan laporan yang berkualitas (Bunga dan Januarti, 2013). Skeptisisme perlu diperhatikan oleh auditor profesional agar hasil pemeriksaan laporan keuangan dapat dipercaya oleh orang yang membutuhkan laporan tersebut. Auditor dituntut untuk selalu cermat dan seksama dalam menggunakan kemahiran profesionalnya. Akan tetapi dalam pelaksanaan praktik jasa auditing yang dilakukan, sebagian masyarakat masih ada yang meragukan tingkat skeptisisme profesional yang dimiliki oleh para 
auditor yang selanjutnya berdampak pada keraguan masyarakat terhadap kualitas laporan keuangan yang dihasilkan (Bunga dan Januarti, 2013).

Audit tenure juga merupakan suatu fenomena yang sering diperdebatkan akibatnya pada kualitas audit di Indonesia. Hal ini terlihat dari peraturan yang terus berkembang mengenai ketentuan lamanya masa perikatan audit. Keputusan Menteri Keuangan Nomor 432/KMK suatu Kantor Akuntan Publik dapat memberikan jasa audit dalam waktu yang paling lama 5 tahun berturut-turut kepada klien, sedangkan bagi auditor paling lama 3 tahun berturut-turut. Keputusan tersebut selanjutnya didukung dengan peraturan BAPEPAM No.VIII.A. 2 (Kep.20/PM/2002). Peraturan mengenai audit tenure kembali diperbaharui dengan dikeluarkannya PMK No. 17 tahun 2008 tentang Jasa Akuntan Publik yang mengatur bahwa pembatasan pemberian jasa KAP diperpanjang menjadi 6 tahun berturut-turut, sedangkan untuk auditor tetap selama 3 tahun berturut-turut.

Argumen tentang hubungan positif tersebut didukung oleh Geiger dan Raghunandan (2002) yang menemukan bahwa pada awal periode auditor, auditor sering mengalami kegagalan melaksanakan tugasnya untuk mengaudit. Pierre dan Anderson (1984) juga menemukan adanya banyak kesalahan audit yang dilakukan auditor pada masa awal perikatan audit karena kurangnya pengalaman yang dimiliki auditor. Supriyono (1998) menyatakan bahwa pengalaman auditor akan meningkat dikarenakan telah terbiasa dengan pekerjaannya sehingga auditor akan bekerja secara efisien dan lebih tahan terhadap tekanan klien. Carcello dan Nagy (2004) menemukan bahwa laporan keuangan yang tidak menampilkan keadaan sebenarnya sering terjadi pada awal pelaksanaan audit. Fenomena tersebut terjadi akibat rendahnya kemampuan auditor dalam mendeteksi salah saji material yang disebabkan oleh kurangnya pengetahuan khusus tentang klien di awal perikatan. Auditor yang memiliki masa perikatan lama lebih dapat mengembangkan pengetahuan khusus mengenai klien serta pemahaman yang lebih dalam tentang bisnis dan risiko bisnis klien yang diaudit.

Adanya hubungan audit tenure dengan kualitas audit menyebabkan audit tenure diduga dapat memoderasi pengaruh pengalaman dan skeptisisme auditor dengan kualitas audit. Selama ini, penelitian mengenai 
kualitas audit telah banyak dilakukan. Namun, pada kenyataannya penelitian mengenai kualitas audit masih sangat penting untuk diteliti karena berhubungan dengan kesesuaian pelaksanaan audit yang dilakukan auditor dengan standar auditing yang telah ditetapkan sehingga pada akhirnya akan menghasilkan kualitas audit yang tinggi. Penjabaran latar belakang tersebut menghasilkan rumusan masalah apakah kualitas audit dipengaruhi oleh pengalaman dan skeptisisme auditor serta apakah audit tenure mampu memoderasi hubungan pengalaman serta skeptisisme auditor dengan kualitas audit.

Standar Audit yang mulai berlaku per 1 Januari 2013 yaitu revisi SPAP yang dilakukan melalui penerbitan exposure draft SPAP. Standar audit terbagi atas 4 bagian yaitu prinsip-prinsip umum dan tanggung jawab, penilaian risiko dan respons terhadap risiko yang telah dinilai, atas entitas dan lingkungannya, bukti audit, penggunaan pekerjaan lain, kesimpulan audit dan pelaporan, dan area-area khusus yang kesemuanya terdiri atas 36 butir pernyataan standar audit. Pada penelitian ini lebih mengacu pada Standar Pernyataan Audit (SPA) 200 mengenai
Tujuan Keseluruhan Auditor Independen dan Pelaksanaan Suatu Audit Berdasarkan Standar Perikatan Audit. Sikap independen seorang auditor diatur dalam Pasal A14 sampai A17 SPA 200. Pasal A18 hingga A22 SPA 200 mengatur sikap skeptisisme profesional yang harus dimiliki oleh seorang auditor.

Standar Audit (SA) 200 dalam pasal A16 menyatakan bahwa suatu perikatan audit menyangkut kepentingan publik dan, oleh karena itu, seperti yang diisyaratkan kode etik, auditor yang bersangkutan harus independen dari entitas yang diauditnya. Auditor harus bersikap jujur kepada semua pihak, baik kepada manajemen, pemilik perusahaan, kreditur, maupun pihak lain yang berkepentingan atas laporan keuangan auditan (Elfarini, 2007). Penelitian Singgih dan Bawono (2010) menyatakan pengalaman merupakan variabel yang paling berpengaruh terhadap kualitas audit dibandingkan dengan variabel independensi, due professional care, dan akuntanbilitas. Penelitian Carcello dan Nagy (2004), Francis (2004), Alim dkk. (2007), dan Sari (2012) juga menemukan pengaruh positif pengalaman dengan kualitas audit.

$\mathrm{H}_{1}$ : Pengalaman auditor berpengaruh positif dengan kualitas audit. 
Skeptisisme profesional auditor merupakan sikap selalu bertanya serta melakukan suatu evaluasi pada bukti audit dengan kritis. Carpenter dkk. (2002) menyatakan bahwa adanya penurunan suatu kualitas audit disebabkan oleh auditor yang kurang bersikap skeptis. Penelitian yang dilakukan oleh Suraida (2005), Margfirah dan Syahril (2008) menemukan adanya hubungan yang signifikan antara sikap skeptis auditor dengan tepatnya opini yang diberikan oleh akuntan publik. Queena (2012) juga menemukan faktor yang berpengaruh positif dengan kualitas audit adalah skeptisisme profesional auditor. Carpenter dkk. (2002) dan (Bunga dan Januarti, 2013) juga menemukan bahwa sikap skeptis yang dimiliki oleh auditor memiliki pengaruh dengan kualitas audit yang dihasilkan. Sikap skeptis seorang auditor tidak hanya digunakan dalam pelaksanaan audit dan penyusunan laporan, namun dalam melakukan berbagai pekerjaan lapangan serta untuk menemukan bukti audit yang kompeten dan cukup. Pada saat melakukan audit, tingkat kesalahan akan semakin kecil apabila sikap skeptis yang dimiliki auditor semakin tinggi (Bell dkk., 2005).
$\mathrm{H}_{2}$ : Skeptisisme profesional auditor berpengaruh positif dengan kualitas audit.

Opini akuntan publik tidak akan memberikan manfaat apapun ketika seorang auditor tidak independen (Mautz dan Sharaf, 1993). Auditor harus menyadari berbagai tekanan yang bermaksud memengaruhi perilakunya dan berangsur-angsur mengurangi kompetensinya. Carey dan Simmnet (2006) menyatakan bahwa kondisi yang paling ekstrim dengan adanya perikatan yang lama adalah timbulnya familiaritas berlebihan yang mendorong terjadinya kolusi diantara auditor dan klien. Bertentangan dengan hal tersebut, Supriyono (1998) menyatakan ketika seorang auditor telah lama bekerja klien akan meningkatkan kompetensi dan pengalamannya. Hal ini dikarenakan auditor akan semakin familiar dengan pekerjaannya hingga pada akhirnya dapat dikerjakan secara efisien dan akan lebih tahan terhadap tekanan klien. Johnson dkk. (2002), Myers dkk. (2003), Januarti (2009), Carpenter dkk. (2002) dan L.M. Gaynor. 2002 dan Efraim (2010) menyatakan bahwa kualitas audit akan meningkat ketika terjadi masa perikatan yang lama. Penelitian tersebut menunjukkan argumen bahwa ketika seorang auditor telah 
lama bertugas, maka akan memiliki pemahaman dan pengalaman untuk merancang prosedur audit yang baik dan benar. Merujuk pada beberapa penelitian yang telah dipaparkan, maka dapat disimpulkan bahwa audit tenure mampu memoderasi pengaruh pengalaman dengan kualitas audit.

$\mathrm{H}_{3}$ : Audit tenure memperkuat hubungan pengalaman auditor dengan kualitas audit.

Sikap skeptis yang dimiliki auditor dapat menyebabkan auditor menggunakan keahlian profesionalnya dengan cermat dan seksama (Yusuf, 2010). Carey dan Simmnet (2006) menyatakan bahwa dampak dari masa perikatan yang lama yakni timbulnya familiaritas berlebihan akan mendorong terjadinya kolusi di antara auditor dan klien. Tingkat kepuasan terlalu tinggi, intervensi yang kurang, prosedur audit yang kurang kuat, dan adanya rasa percaya diri yang berlebihan terhadap klien cenderung muncul sebagai akibat auditor memiliki masa perikatan kerja yang lama dengan klien. Kurangnya intervensi serta kurang kuatnya prosedur audit menunjukkan bahwa sikap skeptis yang dimiliki auditor semakin berkurang. Apabila masa perikatan audit baru dimulai, maka akan memberikan dampak terhadap sikap skeptis auditor. Auditor cenderung lebih berhati-hati dengan klien barunya sehingga akan meningkatkan prosedur auditnya. Peristiwa tersebut menunjukkan bahwa auditor akan meningkatkan sikap skeptisnya. Merujuk pada penelitian seksama (Yusuf, 2010) dan Carey dan Simmnet (2006) yang telah dipaparkan, maka dapat disimpulkan bahwa audit tenure mampu memoderasi hubungan skeptisisme dengan kualitas audit.

$\mathrm{H}_{4}$ : Audit tenure memperkuat hubungan skeptisisme auditor dengan kualitas audit.

\section{METODE PENELITIAN}

KAP yang terletak pada Provinsi Bali yang terdaftar tahun 2015 di Institut Akuntan Publik Indonesia (IAPI) menjadi lokasi penelitian ini. Sampel dipilih menggunakan teknik sampel jenuh. Teknik pengambilan sampel jenuh merupakan teknik pengambilan sampel dengan cara menjadikan seluruh populasi sebagai sampelnya. Berdasarkan teknik sampel jenuh maka seluruh auditor yang bekerja di KAP Provinsi Bali berkesempatan menjadi sampel yakni sebanyak 85 auditor. Metode pengumpulan data primer, yakni kuesioner berupa daftar pernyataan yang akan diberikan kepada responden mengenai pengalaman auditor, skeptisisme 
auditor, audit tenure, dan kualitas audit. Kuisioner yang digunakan dalam penelitian ini merupakan modifikasi kuisioner dari penelitian Elfarini, Eunike Christina (2007).

Teknik analisis datanya menggunakan teknik analisis regresi linier moderasian. Moderated Regression Analysis (MRA) merupakan teknik analisis data aplikasi khusus untuk mengalikan dua atau lebih variabel independen (Lie, 2009). Model regresi dalam penelitian ini ditunjukkan dengan persamaan sebagai berikut:

$$
\begin{aligned}
Y= & a_{1}+\beta_{1} X_{1}+\beta_{2} X_{2}+\beta_{3} X_{3}+\beta_{4} X_{1} X_{3}+ \\
& \beta_{5} X_{2} X_{3}+\mu \ldots \ldots \ldots \ldots \ldots \ldots \ldots . .(1)
\end{aligned}
$$

Keterangan:

$\begin{array}{ll}\mathrm{Y} & : \text { Kualitas audit } \\ \mathrm{a} & : \text { Konstanta } \\ \beta_{1}-\beta_{6} & \text { : Koefisien } \\ \mathrm{X}_{1} & : \text { Pengalaman auditor } \\ \mathrm{X}_{2} & \text { : Skeptisisme auditor } \\ \mathrm{X}_{3} & : \text { Audit tenure } \\ \mu & : \text { Standard Error }\end{array}$

Langkah awal yang digunakan dalam teknik analisis data yakni mengubah data ordinal ke data interval. Data interval yang akan digunakan dalam analisis regresi sehingga data ordinal (skor kuesioner) harus diubah menjadi data interval dengan Method Successive of Internal (MSI) sebelum dilakukan analisis regresi (Lie, 2009).

$\begin{array}{rcr}\text { Uji } & \text { validitas dan uji } \\ \text { reliabilitas } & \text { digunakan } & \text { untuk }\end{array}$

mengukur instrumen pernyataan kuesioner. Apabila nilai $r$ pearson correlation di atas 0,30 maka instrumen dikatakan valid (Sugiyono, 2013:178) dan dikatakan reliabel jika Cronbach's Alpha memiliki nilai di atas 0,60 (Ghozali, 2007:42). Uji normalitas dan heterokedastisitas juga dilakukan sebelum dilakukan uji regresi.

\section{HASIL DAN PEMBAHASAN}

Penyebaran kuesioner yaitu sebanyak 85 eksemplar, namun yang kembali dan dapat digunakan hanya 64 eksemplar. Hal ini terjadi karena tidak seluruh auditor bersedia mengisi kuesioner karena kesibukan yang dimiliki. Statistik deskriptif memberikan informasi mengenai karakteristik variabel penelitian yang terdiri atas jumlah pengamatan, nilai minimum, nilai maksimum, nilai mean, dan standar deviasi. Tabel 1 menunjukkan hasil statistik deskriptif.

Tabel 1 menunjukkan bahwa variabel kualitas audit (Y) memiliki nilai minimum sebesar 12 , nilai maksimum sebesar 23, mean sebesar 17,84, dan standar deviasi sebesar 3,179. Hal ini menunjukkan terjadi perbedaan nilai kualitas audit yang diteliti dengan nilai rata-ratanya sebesar 3,179. 
Tabel 1.

Hasil Statistik Deskriptif

\begin{tabular}{lccccc}
\hline \multicolumn{1}{c}{ Variabel } & N & Min. & Max. & Mean & $\begin{array}{c}\text { Std. } \\
\text { Deviasi }\end{array}$ \\
\hline Kualitas Audit $(\mathrm{Y})$ & 64 & 12 & 23 & 17,84 & 3,179 \\
Pengalaman Auditor $\left(\mathrm{X}_{1}\right)$ & 64 & 8 & 23 & 17,38 & 3,137 \\
Skeptisisme Auditor $\left(\mathrm{X}_{2}\right)$ & 64 & 8 & 24 & 18,16 & 3,163 \\
Audit Tenure $\left(\mathrm{X}_{3}\right)$ & 64 & 8 & 16 & 11,66 & 2,167 \\
\hline Sumber: Data Diolah 2015 & & & & &
\end{tabular}

Variabel pengalaman auditor $\left(\mathrm{X}_{1}\right)$ memiliki nilai minimum sebesar 8, nilai maksimum sebesar 23, mean sebesar 17,38, dan standar deviasi sebesar 3,137. Hal ini menunjukkan terjadi perbedaan nilai pengalaman auditor yang diteliti dengan nilai rataratanya sebesar 3,137. Variabel skeptisisme auditor $\left(\mathrm{X}_{2}\right)$ memiliki nilai minimum sebesar 8 , nilai maksimum sebesar 24, mean sebesar 18,16, dan standar deviasi sebesar 3,163. Hal ini menunjukkan terjadi perbedaan nilai skeptisisme auditor yang diteliti dengan nilai rata-ratanya sebesar 3,163. Variabel audit tenure $\left(\mathrm{X}_{3}\right)$ memiliki nilai minimum sebesar 8 , nilai maksimum sebesar 16, mean sebesar 11,66, dan standar deviasi sebesar 2,167. Hal ini menunjukkan terjadi perbedaan nilai skeptisisme auditor yang diteliti dengan nilai rataratanya sebesar 2,167.

Hasil analisis regresi ditunjukkan pada Tabel 2. Berdasarkan Tabel 2 disusun persamaan regresi sebagai berikut:

$$
\begin{aligned}
& Y=-1,456+0,404 X_{1}+0,311 X_{2}+ \\
& 0,421 X_{3}+\mu \ldots \ldots \ldots \ldots \ldots \ldots \ldots \ldots(2)
\end{aligned}
$$

Berdasarkan persamaan di atas, dapat dijelaskan hal-hal bahwa nilai konstanta sebesar -1,456 menunjukan bahwa nilai kualitas audit akan meningkat sebesar 1,456 satuan apabila nilai pengalaman auditor $\left(\mathrm{X}_{1}\right)$, skeptisisme auditor $\left(\mathrm{X}_{2}\right)$ dan audit tenure $\left(\mathrm{X}_{3}\right)$ sama dengan nol. Nilai koefisien $\beta_{1}=0,404$ berarti menunjukkan nilai kualitas audit (Y) akan meningkat 0,404 satuan jika nilai pengalaman auditor $\left(\mathrm{X}_{1}\right)$ bertambah 1 satuan, dengan asumsi variabel bebas lainnya konstan. Nilai koefisien $\quad \beta_{2}=0,322$ berarti menunjukkan nilai kualitas audit (Y) akan meningkat 0,322 satuan apabila nilai skeptisisme auditor $\left(\mathrm{X}_{2}\right)$ bertambah 1 satuan, dengan asumsi variabel bebas lainnya konstan. Nilai koefisien $\quad \beta_{3}=0,432$ berarti menunjukkan nilai kualitas audit akan meningkat 0,421 satuan jika nilai audit tenure $\left(\mathrm{X}_{3}\right)$ bertambah 1 
satuan, dengan asumsi variabel bebas

lainnya konstan.

Tabel 2.

Analisis Regresi tanpa Variabel Moderasi

\begin{tabular}{|c|c|c|c|c|c|}
\hline \multirow[t]{2}{*}{ Variabel } & \multicolumn{2}{|c|}{$\begin{array}{l}\text { Unstandardized } \\
\text { Coefficients }\end{array}$} & \multirow{2}{*}{$\begin{array}{c}\begin{array}{c}\text { Standardize } \\
\text { d }\end{array} \\
\text { Coefficients } \\
\text { Beta }\end{array}$} & \multirow[t]{2}{*}{$\mathbf{t}$} & \multirow[t]{2}{*}{$\begin{array}{l}\text { Signif } \\
\text { ikansi }\end{array}$} \\
\hline & $\mathrm{B}$ & $\begin{array}{l}\text { Std. } \\
\text { Error }\end{array}$ & & & \\
\hline (Constant) & $-1,456$ & 1,559 & & $\begin{array}{c}- \\
0,921\end{array}$ & 0,364 \\
\hline $\begin{array}{l}\text { Pengalaman } \\
\text { Auditor }\end{array}$ & 0,404 & 0,095 & 0,404 & 4,148 & 0,000 \\
\hline $\begin{array}{l}\text { Skeptisisme } \\
\text { Auditor }\end{array}$ & 0,322 & 0,100 & 0,299 & 3,114 & 0,003 \\
\hline Audit Tenure & 0,432 & 0,139 & 0,290 & 3,017 & 0,004 \\
\hline Adjusted R Square & & & 0,702 & & \\
\hline F hitung & & & 48,092 & & \\
\hline Signifikansi F & & & 0,000 & & \\
\hline
\end{tabular}

Tabel 3.

Analisis Regresi dengan Variabel Moderasi

\begin{tabular}{|c|c|c|c|c|c|}
\hline \multirow[t]{2}{*}{ Variabel } & \multicolumn{2}{|c|}{$\begin{array}{l}\text { Unstandardized } \\
\text { Coefficients }\end{array}$} & \multirow{2}{*}{$\begin{array}{c}\text { Standardize } \\
\text { d } \\
\text { Coefficients } \\
\text { Beta }\end{array}$} & \multirow[t]{2}{*}{$\mathbf{t}$} & \multirow[t]{2}{*}{$\begin{array}{l}\text { Signif } \\
\text { ikansi }\end{array}$} \\
\hline & B & $\begin{array}{l}\text { Std. } \\
\text { Error }\end{array}$ & & & \\
\hline (Constant) & $-8,706$ & 5,365 & & $\begin{array}{c}- \\
1,621\end{array}$ & 0,115 \\
\hline $\begin{array}{l}\text { Pengalaman } \\
\text { Auditor }\end{array}$ & 0,082 & 0,346 & 0,071 & 0,206 & 0,848 \\
\hline $\begin{array}{l}\text { Skeptisisme } \\
\text { Auditor }\end{array}$ & 1,004 & 0,303 & 0,965 & 3,313 & 0,002 \\
\hline $\begin{array}{l}\text { Audit Tenure } \\
\text { Pengalaman }\end{array}$ & 1,152 & 0,535 & 0,792 & 2,141 & 0,037 \\
\hline $\begin{array}{l}\text { Auditor - Audit } \\
\text { Tenure }\end{array}$ & 0,041 & 0,037 & 0,817 & 1,100 & 0,276 \\
\hline $\begin{array}{l}\text { Skeptisisme } \\
\text { Auditor - Audit } \\
\text { Tenure }\end{array}$ & -0.082 & 0,032 & $-1,584$ & 2,374 & 0,021 \\
\hline $\begin{array}{l}\text { Adjusted R Square } \\
\text { F hitung } \\
\text { Signifikansi F }\end{array}$ & & & $\begin{array}{c}0,713 \\
32,118 \\
0,000\end{array}$ & & \\
\hline
\end{tabular}

Sumber: Data Diolah, 2015 
Berdasarkan Tabel 3 dapat disusun persamaan regresi sebagai berikut:

$$
\begin{gathered}
Y=-8,706+0,071 X_{1}+1,004 X_{2+} \\
1,146 X_{3}+0,041 X_{1} X_{3-} 0,075 X_{2} X_{3}+
\end{gathered}
$$

Berdasarkan persamaan di atas, dapat dijelaskan bahwa nilai konstanta sebesar $\quad-8,696$ menunjukan bahwa nilai kualitas audit akan menurun sebesar 8,696 satuan apabila nilai pengalaman auditor $\left(\mathrm{X}_{1}\right)$, skeptisisme auditor $\left(\mathrm{X}_{2}\right)$ dan audit tenure $\left(\mathrm{X}_{3}\right)$ sama dengan nol. Nilai koefisien $\beta_{1}=0,082$ berarti nilai kualitas audit akan meningkat 0,071 satuan jika nilai independensi auditor $\left(\mathrm{X}_{1}\right)$ bertambah 1 satuan, dengan asumsi variabel bebas lainnya konstan. Nilai koefisien $\beta_{2}=1,004$ berarti nilai kualitas audit akan meningkat 1,004 satuan jika nilai skeptisisme auditor $\left(\mathrm{X}_{2}\right)$ bertambah 1 satuan, dengan asumsi variabel bebas lainnya konstan. Nilai koefisien $\beta_{3}=$ 1,152 berarti menunjukkan nilai kualitas audit akan meningkat 1,152 jika nilai audit tenure $\left(\mathrm{X}_{3}\right)$ bertambah 1 satuan, dengan asumsi variabel bebas lainnya konstan. Nilai koefisien $\beta_{4}=0,041$ memperlihatkan bahwa efek dari variabel moderasi adalah positif (memperkuat). Hal ini berarti hubungan pengalaman auditor $\left(\mathrm{X}_{1}\right)$ dan kualitas audit $(\mathrm{Y})$ diperkuat oleh audit tenure. Nilai koefisien koefisien $\beta_{5}=-0,082$ memerlihatkan bahwa efek dari variabel moderasi adalah negatif (memperlemah). Hal ini berarti hubungan skeptisisme auditor $\left(\mathrm{X}_{2}\right)$ dan kualitas audit (Y) diperlemah oleh audit tenure.

Berdasarkan Tabel 2 dan Tabel 3, terlihat perbedaan nilai koefisien determinasi (adjusted $R$ square), dengan menggunakan variabel moderasi menghasilkan koefisien determinasi lebih baik. Hal ini menunjukkan bahwa variabel moderasi memang memengaruhi hubungan variabel independen dan dependen. Nilai adjusted $R$ square tanpa variabel moderasi yang digunakan untuk mengetahui besarnya pengaruh variabel pengalaman auditor, skeptisisme auditor, dan audit tenure dengan kualitas audit, yaitu sebesar 0,713. Hal ini berarti 70,20\% variasi kualitas audit dipengaruhi oleh variasi pengalaman auditor $\left(\mathrm{X}_{1}\right)$, skeptisisme auditor $\left(\mathrm{X}_{2}\right)$ dan audit tenure $\left(\mathrm{X}_{3}\right)$, sisanya sebesar $29,80 \%$ dipengaruhi oleh faktor atau variabel lain di luar model.

Berdasarkan hasil analisis regresi (Tabel 2 dan Tabel 3), menunjukkan bahwa signifikansi $\mathrm{F}$ sebesar 0,000 lebih kecil dari 0,05. Hal ini berarti keseluruhan variabel independen (independensi auditor, skeptisme auditor, dan audit tenure) 
yang digunakan dapat menjelaskan atau memprediksi fenomena kualitas audit pada KAP di Provinsi Bali, sehingga dapat diambil kesimpulan yakni model dalam penelitian ini layak untuk diteliti. Uji $t$ juga dilakukan untuk mengetahui pengaruh masing-masing variabel independen dan moderasi secara individual pada variabel dependen. Langkah pertama yang dilakukan memformulasikan hipotesis, menetapkan taraf nyata, yaitu $5 \%$, dan menetapkan kriteria keputusan.

Berdasarkan Tabel 2 dan Tabel 3, maka nilai signifikansi tiap hipotesis dapat dirangkum pada Tabel 4.

Tabel 4.

Hasil Uji Hipotesis

\begin{tabular}{lcc}
\hline \multicolumn{1}{c}{ Hipotesis } & Signifikansi & Keterangan \\
\hline $\begin{array}{l}\text { Pengalaman auditor } \\
\text { berpengaruh pada }\end{array}$ & 0,001 & Diterima \\
$\begin{array}{l}\text { kualitas audit } \\
\text { Skeptisisme auditor } \\
\text { berpengaruh positif pada } \\
\text { kualitas audit }\end{array}$ & 0,004 & Diterima \\
$\begin{array}{l}\text { Audit tenure memoderasi } \\
\text { pengaruh pengalaman } \\
\text { pada kualitas audit } \\
\text { Audit tenure memoderasi } \\
\text { pengaruh skeptisisme } \\
\text { pada kualitas audit }\end{array}$ & 0,242 & Ditolak \\
\hline
\end{tabular}

Sumber: Data Primer (Data Diolah, 2015)

Berdasarkan Tabel 4, maka dapat diambil kesimpulan bahwa hipotesis yang diterima yakni $\mathrm{H}_{1}, \mathrm{H}_{2}$, dan $\mathrm{H}_{4}$. Hal ini terlihat dari nilai signifikansinya yang tidak lebih besar dari 0,05. Nilai signifikansi $\mathrm{H}_{1}, \mathrm{H}_{2}$, dan $\mathrm{H}_{4}$ secara berturut-turut yaitu 0,001, 0,004, dan 0,025. Nilai signifikansi $\mathrm{H}_{3}$ yaitu 0,242 dan lebih besar dari 0,05 menyebabkan hipotesis ketiga ditolak.

Hasil uji parsial pengaruh pengalaman auditor $\left(\mathrm{X}_{1}\right)$ pada kualitas audit (Y) pada Tabel 2 diperoleh $p$-value $=0,000$ tidak lebih besar dari a $=0,05$ Hal ini menunjukkan bahwa kualitas audit dipengaruhi secara signifikan oleh pengalaman auditor. Nilai koefisien 
regresi pengalaman auditor $\left(\mathrm{X}_{1}\right)$ sebesar $\quad 0,397 \quad$ menunjukkan pengaruh yang diberikan pengalaman auditor pada kualitas audit yakni positif. Hasil ini menerima hipotesis $\mathrm{H}_{1}$ yang menyatakan pengalaman auditor berpengaruh positif dan signifikan pada kualitas audit. Auditor dengan pengalaman yang tinggi menghasilkan kualitas audit yang dihasilkan semakin baik, sebaliknya apabila tingkat pengalaman auditor rendah maka kualitas audit yang dihasilkan akan semakin menurun. Berdasarkan penemuan tersebut, maka dapat digambarkan bahwa pengalaman auditor memiliki peran dalam menentukan kualitas audit yang dihasilkan oleh auditor di KAP Provinsi Bali. Temuan ini konsisten dengan penelitian oleh Sari (2012) yang menemukan bahwa independensi auditor berpengaruh positif terhadap kualitas audit. Penelitian Carcello dan Nagy (2004), Francis (2004), dan Alim dkk. (2007) juga menemukan pengaruh positif pengalaman pada kualitas audit.

Hasil uji parsial pengaruh skeptisisme auditor $\left(\mathrm{X}_{2}\right)$ pada kualitas audit (Y) pada Tabel 2 diperoleh $p$ value sebesar 0,004 tidak lebih besar dari $\mathrm{a}=0,05$. Hal ini menunjukkan jika kualitas audit dipengaruhi secara positif oleh skeptisisme auditor. Nilai koefisien sebesar 0,292 menunjukkan skeptisisme auditor memberikan pengaruh positif skeptisisme auditor pada kualitas audit. Hasil ini menerima hipotesis $\mathrm{H}_{2}$ yang menyatakan skeptisisme auditor berpengaruh positif dan signifikan pada kualitas audit. Auditor dengan sikap skeptis yang tinggi akan meningkatkan kualitas audit yang dihasilkannya, sebaliknya kualitas audit akan menurun saat auditor kurang memiliki sikap skeptis (Carpenter dkk., 2002). Berdasarkan penemuan tersebut, maka dapat digambarkan bahwa skeptisisme auditor memiliki peran dalam menentukan kualitas audit yang dihasilkan oleh auditor di KAP Provinsi Bali. Penelitian ini konsisten dengan penelitian Margfirah dan Syahril (2008) menemukan bahwa di antara skeptisisme profesional auditor dan ketepatan pemberian opini auditor oleh akuntan publik memiliki hubungan yang signifikan. Pada saat pemberian opini telah tepat, maka secara otomatis kualitas audit juga akan semakin baik. Queena (2012) juga menemukan faktor yang berpengaruh positif terhadap kualitas audit adalah skeptisisme profesional auditor.

$$
\text { Hasil uji moderasi }
$$
pengalaman auditor dan audit tenure $\left(\mathrm{X}_{1} \mathrm{X}_{3}\right)$ pada kualitas audit diperoleh $p$ - 
value sebesar 0,231 (Tabel 3) tidak lebih kecil dari $a=0,05$. Hal tersebut memerlihatkan bahwa audit tenure tidak mampu memoderasi pengaruh pengalaman auditor pada kualitas audit. Hasil ini menunjukkan bahwa $\mathrm{H}_{3}$ yang menyatakan audit tenure memerlemah pengaruh pengalaman auditor pada kualitas audit ditolak. Hal tersebut sejalan dengan hasil penelitian yang dilakukan oleh Wibowo dan Rossieta (2009) yang menunjukkan bahwa audit tenure tidak berpengaruh pada kualitas audit. Fenomena yang ditunjukkan oleh penelitian ini juga mengindikasikan bahwa pengalaman yang dimiliki auditor ternyata tidak menurun begitu saja ketika terjadi masa perikatan yang lama diantara dirinya dan klien.

Hasil uji moderasi skeptisisme auditor dan audit tenure $\left(\mathrm{X}_{2} \mathrm{X}_{3}\right)$ pada kualitas audit diperoleh p-value sebesar 0,022 (Tabel 3) tidak lebih besar dari $a=0.05$. Hal ini memerlihatkan bahwa audit tenure mampu memoderasi pengaruh skeptisisme auditor pada kualitas audit. Nilai koefisien regresi skeptisisme auditor dan audit tenure $\left(\mathrm{X}_{2} \mathrm{X}_{3}\right)$ sebesar $-0,094$ menjelaskan bahwa audit tenure memerlemah pengaruh skeptisisme auditor pada kualitas audit. Hasil ini menerima hipotesis $\mathrm{H}_{4}$ yang menyatakan audit tenure memperlemah pengaruh skeptisisme auditor pada kualitas audit. Hal ini mengindikasikan bahwa ketika terjadi masa perikatan yang lama di antara klien, akan menurunkan sikap skeptis auditor yang selanjutnya dapat menurunkan kualitas audit yang dihasilkan. Hasil ini konsisten dengan penelitian Carey dan Simmnet (2006) yang menyatakan dampak dari masa perikatan yang lama yakni timbulnya familiaritas berlebihan yang mendorong terjadinya kolusi diantara auditor dan klien serta kurang kuatnya prosedur audit yang dimiliki. Prosedur yang kurang kuat menunjukkan bahwa auditor kurang bersikap skeptis.

\section{SIMPULAN DAN SARAN}

Berdasarkan hasil analisis dan pembahasan yang telah dilakukan, maka simpulan yang diperoleh adalah kualitas audit di KAP Provinsi Bali dipengaruhi secara positif oleh pengalaman auditor dan skeptisisme auditor. Audit tenure tidak mampu memoderasi pengaruh pengalaman auditor dengan kualitas audit auditor di KAP Provinsi Bali, sedangkan audit tenure mampu memoderasi pengaruh skeptisisme auditor dengan kualitas audit auditor di KAP Provinsi Bali.

Beberapa saran yang dapat diberikan, yakni: bagi peneliti 
selanjutnya disarankan untuk menggunakan metode penelitian dengan pengamatan langsung atau metode lainnya, karena dengan menggunakan metode kuesioner terkadang responden memberikan pernyataan dengan asal dan tidak menggambarkan kondisi sebenarnya. Hasil Adjusted $R$ square sebesar $70,2 \%$ menunjukkan bahwa masih ada variabel lain yang dapat memengaruhi kualitas audit sehingga peneliti selanjutnya dapat menambahkan variabel yang memengaruhi kualitas audit. Bagi auditor di Kantor Akuntan Publik Provinsi Bali Penelitian ini menemukan bahwa audit tenure dapat memperlemah sikap skeptis yang dimiliki auditor. Bagi auditor sendiri, hendaknya selalu menjaga kinerjanya agar tidak mudah terpengaruh dengan adanya masa perikatan yang lama sehingga kualitas audit yang dihasilkan dapat memberikan manfaat bagi pihakpihak yang memerlukan laporan keuangan auditan.

\section{REFERENSI}

Agustin, Aulia. 2013. Pengaruh Pengalaman, Independensi, dan Due Profesional Care Auditor terhadap Kualitas Audit Laporan Keuangan Pemerintah. Artikel. Program Studi Akuntansi Fakultas Ekonomi Universitas Negeri Padang.
Alim, M. N, T. Hapsari, dan L. Purwanti 2007. Pengaruh Kompetensi dan Independensi terhadap Kualitas Audit dengan Etika Audit sebagai Variabel Moderasi. Simposium Nasional Akuntansi $X$. Unhas Makassar, 26-28 Juli 2007.

Badjuri, Achmat. 2011. Faktor-faktor yang Berpengaruh terhadap Kualitas Audit Auditor Independen pada Kantor Akuntan Publik (KAP) di Jawa Tengah. Dinamika Keuangan dan Perbankan. 3 (2), pp: 183197.

Bell, T.B., M.E. Peecher, dan H. Thomas. 2005. The 21st Century Public Company Audit. New York, NY: KPMG LLP.

Bunga Pratiwi, Astari dan Indira Januarti. 2013. Pengaruh Faktor-faktor Skeptisisme Profesional Auditor terhadap Pemberian Opini (Studi Empiris pada Pemeriksa BPK RI Provinsi Jawa Tengah). Diponegoro Journal of Accounting. 2 (1), pp: 1-14.

Carcello, J.V., dan A.L. Nagy. 2004. Audit Firm tenure and Fraudulent Financial Reporting. Auditing : A Journal of Accounting Practice and Theory, 23(2) : 5569.

Carey,P., dan R. Simnett.2006. Audit Tenure and Audit Quality. The Accounting Review 81(3) : 653676.

Carpenter, T., C. Durtschi dan L.M. Gaynor. 2002. The Role of Experience in Professional Skepticism, Knowledge Acquisition, and Fraud Detection. Working paper.

DeAngelo, L.E. 1981. Auditor Independence, "Low Billing" and 
Disclosure Regulation. Journal of Accounting and Econo mics. August. Pp. 113-127

Deis, Donald R. Jr. dan Gary A. Giroux. 1992. Determinants of Audit Quality In The Public Sector. The Accounting Review, Vol. 67 No. 3 ( July). Pp. 462479.

Efraim. 2010. Pengaruh Tenure KAP dan Reputasi Auditor terhadap Kualitas Audit di BEI. Jurnal Ilmiah Fakultas Ekonomi Universitas Jenderal Sudirman. Purwokerto, Yogyakarta.

Elfarini, Eunike Christina. 2007. Pengaruh Kompetensi dan Independensi Auditor Terhadap Kualitas Audit : Studi Empiris Pada Kantor Akuntan Publik di Jawa Tengah. Skripsi. Universitas Negeri Semarang, Semarang.

Francis, J. R. 2004. What do we know about audit quality?. The British Accounting Review 26, 345-368.

Geiger, M. A. dan K. Raghunandan. 2002. "Audit tenure and audit reporting failures". Auditing: A Journal of Practice \& Theory (March): pp.67-78

Ghozali, Imam. 2006. Aplikasi Analisis Multivariate dengan Program SPSS. Badan Penerbit Universitas sumatera Diponegoro, Semarang.

Januarti, Indira. 2009. Analisis Pengaruh Faktor Perusahaan, Kualitas Auditor, Kepemilikan Perusahaan terhadap Penerimaan Opini Audit Going Concern (Perusahaan Manufaktur yang Terdaftar di Bursa Efek Indonesia). Simposium Nasional Akuntansi XII. Unoversitas Sriwijaya Palembang, 4-6 November 2009.
Johnson, V.E., I.K. Khurana, dan J.K. Reynolds. 2002. Audit Firm Tenure and The Quality of Financial Reports. Contemporary Accounting Research 19(4) : 637660.

Lie, Liana. 2009. Penggunaan MRA dengan SPSS untuk Menguji Pengaruh Variabel Moderatoring terhadap Hubungan antara Variabel Independen dan Variabel Dependen. Jurnal Teknologi Informasi DINAMIK, 14,(2),90-97.

Marghfirah dan Syahril. 2008. Hubungan Skeptisme Profesional Audit dan Situasi Audit, Etika, Pengalaman, serta Keahlian Audit dengan Ketepatan Pemberian Opini Auditor oleh Akuntan Publik. Simposium Nasional Akuntansi $X I$. Pontianak.

Mautz, R.K dan H.A. Sharaf. 1993. The Philosophy of Auditing. Sarasota : American Accounting Association.

Mayangsari, S. 2003. Pengaruh Keahlian Audit dan Independensi terhadap Pendapat Audit: Sebuah Kuasi eksperiman, Jurnal Riset Akuntansi Indonesia, Vol. 6 No. 1.

Myers, J.N., L.A. Myers, dan C.T. Omer. 2003. Exploring the term of the auditor- client relationship and the quality of earnings: A case for mandatory auditor rotation. The Accounting Review, 78 (3), 779-799.

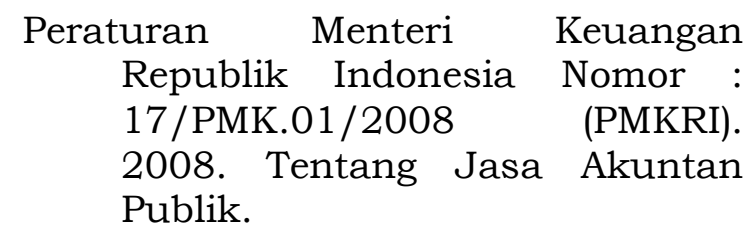


Pierre, K. dan J.A. Anderson. 1984. An Analysis of The Factors Associated With Lawsuits Against Public Accountants. The Accounting Review, April: 242263.

Piorina Fortuna Sari, Ni Putu dan I Wayan Ramantha. 2015. Pengaruh Sikap Skeptisme, Pengalaman Audit, Kompetensi, dan Independensi Auditor pada Kualitas Audit. EJurnal Akuntansi Universitas Udayana. 11 (2), pp: 470-482.

Queena, Precilia Prima dan Abdul Rohman. 2012. Analisis FaktorFaktor Yang Mempengaruhi Kualitas Audit Aparat Inspektorat Kota/Kabupaten Di Jawa Tengah. Journal of Accounting, Vol. 1, No. 2, Tahun 2012, Halaman 1-12.

Ramdanialsyah. 2010. Pengaruh Tekanan Klien, Pengalaman Auditor dan Profesionalisme Auditor terhadap Kualitas Audit (Studi Kasus pada Kantor Akuntan Publik di Jakarta Selatan). Skripsi. Jakarta: S1 Jurusan Akuntansi Fakultas Ekonomi dan Bisnis Universitas Islam Negeri Syarif Hidayatullah.

Sari, Rosalina. 2012. Pengaruh Kompetensi dan Independensi terhadap Kualitas Audit. Jurnal Akuntansi Vol. 1, No. 2.

Singgih, Elisha Muliani dan Icuk Rangga Bawono. 2010. Pengaruh Independensi, Pengalaman, Due
Professional Care dan Akuntabilitas Terhadap Kualitas Audit. Simposium Nasional Akuntansi XIII. Purwokerto.

Sugiyono. 2013. Metode Penelitian Bisnis. Bandung: C.V. Alfabeta.

Suraida, Ida. 2005. Pengaruh Etika, Kompetensi, Pengalaman Audit, dan Risiko Audit terhadap Skeptisisme Profesional Auditor dan Ketepatan Pemberian Opini Akuntan Publik. Jurnal Sosiohumaniora, Vol. 7, No. 3, hal : 186-202.

Supriyono, R.A. 1998. Pemeriksaan Akuntansi (Auditing): FaktorFaktor Yang Mempengaruhi Independensi Penampilan Akuntan Publik. Yogyakarta: Salemba Empat.

Yusuf, Haryono. 2010. Auditing (Pengauditan). Yogyakarta : STIE YKPN.

Winantyadi, Ndaru dan Indarto Waluyo. 2014. Pengaruh Pengalaman, Keahlian, Situasi Audit, dan Etika terhadap Skeptisisme Profesional Auditor. Jurnal Nominal. 3 (1), pp: 14-34. 